\title{
PROBLEMATIZANDO A TEMÁTICA DO TRÁFICO DE ANIMAIS SILVESTRES E DO CATIVEIRO ILEGAL NA SALA DE AULA: PERSPECTIVAS DA EDUCAÇÃO AMBIENTAL NA PERCEPÇÃO DE PROFESSORES DA EDUCAÇÃO BÁSICA
}

\author{
Camila Alves Islas ${ }^{1}$ \\ Greice Maia Behling ${ }^{2}$
}

Resumo: Esta pesquisa busca problematizar a temática do tráfico e cativeiro ilegal de animais silvestres na sala de aula, possibilitando desenvolver propostas de atividades de formação continuada para docentes. A partir de questionários, investiga-se as concepções e compreensões de 21 professores sobre o assunto em escolas municipais do Capão do Leão, RS. Logo, apresentam-se três categorias de análise que discutem como os sujeitos definem e compreendem conceitos basais relacionados aos animais silvestres, o que conhecem sobre as atividades ilegais estudadas e como têm abordado o tema no espaço escolar. Conclui-se que a problemática dos animais silvestres na sociedade contemporânea apresenta pouca permeabilidade na sala de aula e na escola, o que a destaca como uma temática a ser trabalhada pelos sujeitos da educação ambiental e em processos de formação continuada de professores.

Palavras-chave: Educação Ambiental; Formação de Professores; Tráfico e cativeiro ilegal de animais silvestres.

\section{DISCUSSING ILLEGAL WILDLIFE TRAFFICKING AND CAPTIVITY SUBJECT IN THE CLASSROOM: PERSPECTIVES OF ENVIRONMENTAL EDUCATION IN THE PERCEPTION OF PRIMARY SCHOOL TEACHERS}

\begin{abstract}
This research seeks to question the subject of illegal wildlife trafficking and captivity in the classroom, to enable the development of education activities for teachers. From surveys, conceptions and understandings of 21 teachers are investigated about the subject in elementary schools from Capão do Leão municipality, Brazil. Them, three categories of analysis are presented to discuss how teachers define and understand baseline concepts related to wild animals, what knowledge they have about the illegal activities studied and how they have addressed the subject at school. In conclusion, the problem of wild animals in contemporary society shows little permeability in the classroom and at school as a whole, which stands as a theme to be worked by the subjects of environmental education and continuing education process for teachers.
\end{abstract}

Keywords: Environmental Education; Teacher training; Illegal transport and captivity of wild animals.

\section{Introdução}

O Brasil é reconhecido mundialmente como um país que apresenta grande biodiversidade de organismos, inclusive quando considerada sua fauna de vertebrados

\footnotetext{
${ }^{1}$ Doutoranda em Ecologia na Universidade Estadual de Campinas (UNICAMP), Instituto de Biologia, Programa de Pós-graduação em Ecologia. camilaai@ hotmail.com

${ }^{2}$ Doutoranda em Educação Ambiental Fundação Universidade Federal do Rio Grande (FURG), Instituto de Educação, Programa de Pós-graduação em Educação Ambiental. biogre@ gmail.com
} 
(LEWINSOHN; PRADO, 2005). Essa característica, somada ao extenso território do país e a baixa capacidade de fiscalização que os órgãos ambientais apresentam, resultam em um cenário preocupante de práticas criminosas relacionadas aos animais silvestres, como a caça, maus tratos, tráfico e cativeiro ilegal, dentre outros (DESTRO, 2012).

Os animais silvestres são definidos pelo Instituto Brasileiro do Meio Ambiente e dos Recursos Naturais Renováveis (IBAMA) como as espécies que ocorrem naturalmente dentro dos limites do território Brasileiro e suas águas jurisdicionais (IBAMA, 1998), os quais tem sua proteção garantida pela lei desde 1967 (Lei Federal de Proteção à Fauna no 5.197). Na esfera infraconstitucional, a Lei de Crimes Ambientais ( $\mathrm{n}^{\circ}$ 9.605/98) regulamenta a norma constitucional dispondo sobre as sanções penais e administrativas derivadas de condutas lesivas ao meio ambiente, tipificando nos artigos 29 a 37 os crimes contra a fauna. Ainda assim, o comércio desses animais caracteriza-se como a segunda maior ameaça à fauna brasileira (REDFORD, 1992), representando cerca de 5\% a $15 \%$ do comércio ilegal mundial de animais silvestres (RENCTAS, 2001).

O tráfico de animais silvestres ocupa, em volume de recursos financeiros, a terceira colocação entre os principais mercados ilegais, perdendo apenas para o de armas e o de drogas (RENCTAS, 2001), e movimenta mais de 10 a 20 bilhões de dólares por ano (LAVACA et al., 2000; WEBSTER, 1997). A maioria dos indivíduos traficados no país são capturados nas áreas rurais, próximas a comunidades pobres, de onde são escoados para os centros urbanos das regiões Sul, Sudeste e para outros países. No transporte, realizado em péssimas condições, muitos animais sofrem maus tratos, são cegados, mutilados e embriagados para não denunciarem a atividade ilegal ao fazer barulho e para parecerem mais mansos aos consumidores. A situação resulta em uma mortalidade de $90 \%$ dos animais transportados (RENCTAS, 2001). Esse panorama é facilitado pelo quadro econômico pouco favorável encontrado nas regiões alvo, nas quais há baixa escolaridade, poucas opções de atividades econômicas produtivas e não são encontradas alternativas de renda. Muitas famílias no Brasil ainda vivem desse comércio ilegal, principalmente por questões de sobrevivência (LACAVA et al., 2000).

Diante deste cenário, além de fazer cumprir a lei ou revogar as falhas que possam favorecer a degradação da fauna, há uma demanda da inserção da Educação Ambiental (EA), de modo a minimizar as práticas danosas ao meio ambiente. Considera-se a relevância da EA como mediadora desse caminho, no processo de construção de consciência crítica para a problemática dos animais silvestres na sociedade contemporânea, promovendo a reflexão de que as transgressões são fomentadas pelos próprios cidadãos consumidores e buscando a pró-atividade na preservação da fauna silvestre brasileira, na busca de uma mudança deste paradigma consolidado na sociedade contemporânea. Guimarães (2004) coloca que, sob uma perspectiva crítica, a EA é capaz de potencializar espaços de discussão, oxigenando discursos e conceitos estruturados na sociedade acerca dos problemas socioambientais. A partir deste estudo, tramou-se a EA à perspectiva de docentes, possibilitando outros caminhos para as discussões acerca do tráfico e cativeiro ilegal de animais silvestres. Desse modo, acredita-se que seja possível superar este entendimento social sobre o assunto que dificulta a construção de um senso crítico.

A escola e os professores são considerados parte fundamental no desafio de possibilitar ao aluno, no seu cotidiano, a reflexão sobre temas da EA (JACOBI, 2004), em uma perspectiva transversal e interdisciplinar, como estabelecido na Lei Federal de n 9.795 de 1999, no Programa Nacional de Educação Ambiental (PRONEA, 2005) e de acordo com os Parâmetros Curriculares Nacionais (PCN - BRASIL, 1998b). Sob o olhar 
da EA, a escola pode oferecer subsídios para pensar os problemas ambientais encontrados na sociedade, por meio da aproximação entre o conhecimento apresentado, a teoria, e aquilo que os sujeitos vivenciam, a pratica. De acordo com Freire (1980) e Tamaio (2002), quando o ensino alcança essa aproximação, permite que o aluno reflita seu papel como cidadão nas relações com o meio ambiente e com a sociedade, o que possibilita que estes modifiquem a realidade e sejam modificados por ela por meio do autoquestionamento de suas ações.

O professor é sujeito fundamental no processo de formação do aluno enquanto esse cidadão crítico, que descobre as potencialidades para o exercício de sua cidadania e ressignifica seus comportamentos mediante as dificuldades socioambientais presenciadas no seu cotidiano (FREIRE, 2014). Ações pedagógicas que tenham como finalidade fomentar esse processo devem exceder a mera transmissão de conhecimentos ecologicamente corretos, envolvendo os educandos com a causa ambiental, cognitiva e afetivamente, buscando transformar práticas individuais e coletivas, através da mudança de valores sociais, como o consumismo (GUIMARÃES, 2004). No entanto, para que o docente possa atuar de forma satisfatória nesse processo é preciso que este reconheça a relevância das temáticas abordadas pela EA e que possua o conhecimento necessário para tratar dos assuntos na sala de aula. Nesse sentido, atividades de formação continuada são excelentes ferramentas para possibilitar ao professor maior contato com temas que não foram trabalhados durante sua formação e também para familiarizá-lo com as atualizações que as áreas sofrem ao longo do tempo (TARDIF, 2002). Assim, este estudo tem como objetivo principal problematizar a temática do tráfico de animais silvestres e do cativeiro ilegal na sala de aula, a partir das concepções e compreensões de professores da educação básica sobre o assunto. Pretende-se observar, assim, o interesse e existência de subsídios para trabalhar este tema transversal na escola, para que se possa desenvolver, posteriormente, atividades de formação continuada com os docentes de escolas públicas acerca da temática.

\section{Metodologia}

Em um contexto regional, no sul do Rio Grande do Sul, no município do Capão do Leão, o Núcleo de Reabilitação da Fauna Silvestre e Centro de Triagem de Animais Silvestres da Universidade Federal de Pelotas (NURFS/CETAS/UFPEL), atua, desde 1998, no manejo, tratamento veterinário e destinação de animais silvestres. Os animais atendidos são oriundos, principalmente, de atividades de fiscalização de órgãos públicos (IBAMA e Polícias Federal, Rodoviária Federal, Civil e Brigada Militar, em especial, a Companhia Ambiental), que atuam em operações contra o tráfico e cativeiro ilegal, e de acidentes ambientais, como atropelamentos. Até 2015, pelo menos quinze mil animais já foram recebidos pela Instituição que é referência no estado.

Este artigo originou-se das atividades de EA de um projeto de extensão desenvolvido na região de abrangência direta do NURFS/CETAS/UFPEL (Behling e Islas, 2014). A necessidade do projeto surgiu a partir da realidade percebida dentro da Instituição, na qual centenas de animais silvestres são recepcionados por mês provenientes de apreensões ocorridas no município do Capão do Leão e em municípios do entorno. Ao longo dos 15 anos de atuação do NURFS/CETAS/UFPEL na região, percebeu-se que grande parte da fauna apreendida é traficada ou mantida em cativeiro por pessoas de todas as idades, gêneros e classe social, que não conhecem o conceito de animais silvestres, não reconhecem a ilegalidade das atividades e não possuem qualquer 
conhecimento sobre os malefícios dessas ações para o animal e para o meio ambiente, o que destacou a necessidade de atividades educativas que tratem da temática.

Nesse contexto, como projeto piloto, atividades de EA com foco nos animais silvestres e sua conservação foram realizadas, primeiramente, nas cinco escolas públicas municipais mais próximas ao NURFS/CETAS/UFPEL, região que possui maior contato com o estabelecimento e possui influência do tráfico e cativeiro ilegal de fauna. $\mathrm{O}$ primeiro contato com as escolas foi realizado por telefone com as coordenadoras pedagógicas ou diretoras das escolas, no qual buscou-se apresentar as atividades propostas, bem como seus principais objetivos, metodologias a serem utilizadas e as faixa etárias mais adequadas. Prontamente as cinco escolas contatadas demonstraram interesse no projeto e entraram em contato com os docentes responsáveis pelas disciplinas de ciências, para que estes cedessem suas aulas para proporcionar a realização das atividades. Após, uma reunião ocorreu em cada um dos colégios para alinhar o projeto às expectativas das escolas e acertar os últimos detalhes.

As atividades de EA foram realizadas com alunos de $3^{\circ}$ a $9^{\circ}$ ano do ensino fundamental, uma vez por semana, durante quatro semanas, sempre no horário das aulas de ciências, em dois períodos de 40 minutos cada, totalizando 6 horas aproximadamente. Todos os professores das escolas abrangidas pelo projeto, independente da sua área de ensino, foram convidados a participar por meio de um questionário que continha perguntas discursivas relacionadas ao tema da fauna silvestre, seu cativeiro e comércio ilegal, a saber:

1. Você sabe qual é a diferença entre um animal silvestre, doméstico e exótico? Explique. 2. Você possui animais de estimação? Quais? 3. Por que você possui esses animais de estimação? 4. Se você ainda não possui, gostaria de possuir? Qual tipo de animal? 5. Você possui ou conhece alguém que possui pássaros em gaiolas? Sabe se são legalizados? 6. Sabe o que é necessário fazer para possuir um animal diferente dos tradicionais em casa? Gostaria de ter um? Qual? 7. Considera importante não capturar animais livres? Por quê? 8. Já havia sido informado que é ilegal manter um animal silvestre em cativeiro sem a devida autorização? Quem informou? 9. Explique o que é, para você, tráfico de animais. Dê exemplos das consequências. 10. Você já participou de alguma palestra ou já viu alguma campanha sobre esse tema? Onde? 11. Acha importante a realização de atividades desse tipo (como as realizadas neste projeto)? Já trabalhou de alguma forma este assunto em suas aulas? Por quê?

Os professores foram incluídos no projeto por acreditar-se que estes são parte fundamental no processo de formação dos alunos (TARDIF, 2002). Entende-se que o papel do docente na formação do aluno é essencialmente relevante em atividades de EA que são propostas por sujeitos externos à dinâmica escolar, como é o caso aqui estudado. Compreende-se que a efetividade desse tipo de atividade depende de um processo contínuo de formação e discussão com os alunos, o que só pode ser alcançado com a colaboração dos professores. Essa aliança mostra-se especialmente importante quando se trata de temas que, para serem analisados e discutidos criticamente pelos alunos, necessitam que haja mais do que apenas o repasse de informações, mas uma sensibilização dos sujeitos perante o assunto estudado. Essa sensibilização é, muitas vezes, necessária para que se possa gerar, posteriormente, mudanças de valores e de paradigmas legitimados pela sociedade contemporânea. Muitos dos temas tratados pela EA possuem essas características. Deste modo, como é essencial que os docentes também 
sejam foco de atividades e pesquisas relacionadas a EA, neste artigo, os professores tornam-se sujeitos de pesquisa.

Ao todo, 21 professores responderam o questionário entregue. As respostas das questões constituíram o corpus teórico, analisado por meio do método de Análise Textual Discursiva - ATD (MORAES; GALLIAZI, 2006), escolhido pela sua possibilidade de imersão e diálogo com o material da análise e também de compreensão construída através da escrita. Os discursos presentes nas respostas foram desmembrados e reagrupados em unidades de significado de acordo com o tema exposto e objetivo a ser alcançado, transformando os dados brutos em uma representação do conteúdo (MORAES, 1999). Após essa etapa, chamada também de "desconstrução", procedeu-se à reconstrução do texto. Foram estabelecidas relações entre as unidades de significado encontradas, utilizadas na construção de novas compreensões em relação ao fenômeno estudado, formando categorias de análise. Para construção das categorias foi utilizado o método indutivo, que parte dos dados, construindo categorias que "emergem" da própria análise.

A última parte da análise refere-se à produção de um metatexto que combina descrição com interpretação, organizado a partir das categorias construídas ao longo da análise. A ATD é entendida como uma metodologia qualitativa de análise que valoriza tanto a descrição quanto a interpretação dos dados e que possibilita a reconstrução teórica e de significados a partir das perspectivas de uma diversidade de sujeitos envolvidos nas pesquisas (MORAES; GALLIAZI, 2006).

Portanto, a partir da análise do corpus teórico, a pesquisa direcionou-se para três categorias de análise e seus respectivos metatextos, descritos e interpretados no próximo tópico. A primeira, a qual se denominou "Definições e concepções: primeiros passos para alcançar uma EA", analisa como os sujeitos definem e compreendem os conceitos mais basais relacionados aos animais silvestres, seus habitats e seus representantes. A segunda categoria, "O tráfico e a cultura do cativeiro de animais silvestres na perspectiva dos docentes" analisa as concepções e o conhecimento dos sujeitos sobre os diferentes aspectos das atividades ilegais estudadas. Por último, a categoria "A importância da EA em sala de aula e o papel do professor na construção de um entendimento crítico da temática dos animais silvestres" analisa como o assunto tem sido abordado no universo escolar e que ações tem efetivamente sido realizadas na busca por uma visão mais crítica e bem informada, assim como, por atitudes mais conscientes com relação à problemática da fauna.

\section{Resultados e discussão}

\subsection{Definições e concepções: primeiros passos para alcançar uma EA}

O tráfico e o cativeiro ilegal de animais silvestres são assunto de extrema relevância para a sociedade contemporânea e ações conservacionistas tornam-se urgentes para a manutenção das espécies silvestres. Assim, para que que se possa pensar em uma Educação Ambiental (EA) que provoque mudanças de atitudes, de valores e de paradigmas, e que resulte em gerações de jovens mais críticos e capacitados para lidar com as problemáticas ambientais atuais, é preciso, primeiramente, fortalecer as bases conceituais referentes às temáticas que pretendem ser discutidas. Assim, se apresentam nesta categoria, na perspectiva dos docentes, definições e concepções tramadas ao conceito de animais silvestres.

Os sujeitos associam os animais silvestres com "natureza", "matas", “campos", "florestas" e "selvas"; como animais que "vivem no seu habitat natural", "livres", "sem contato com o ser humano". Como exemplos de animais silvestres foram citados os 
pássaros, o leão, o tigre e a onça. Constatou-se, assim, que os conceitos de animais silvestres apresentado pelos professores assemelham-se à definição da Portaria do IBAMA no 93, de 07 de julho 1998, no sentido de que são animais que nascem e se desenvolvem nos ambientes naturais e que não sofreram processos de domesticação.

$\mathrm{O}$ animal silvestre pertence à fauna de uma região (Professor 2).

A concepção dos professores de uma fauna que vive livre e necessita dos seus habitats para sobreviver mostra-se bastante benéfica para a construção de uma visão problematizadora por parte dos alunos sobre a problemática contemporânea dos animais silvestres na sociedade. A imagem do animal silvestre como um ser livre, que precisa estar na natureza para sobreviver, questiona a necessidade que as pessoas sentem de possuir um animal de estimação, silvestre ou exótico, e a ideia de que esse pode viver sem prejuízos de sua saúde física ou mental dentro de uma gaiola ou aquário. É possível ainda, a partir dessa concepção, destacar a necessidade de conservar os ecossistemas nos quais os animais silvestres vivem, para que estes possam sobreviver as pressões ambientais e antrópicas.

Animal silvestre está livre, em matas e florestas (Professor 4). Os silvestres necessitam do seu habitat natural para sobreviver (Professor 8).

Ainda que a concepção dos docentes sobre os animais silvestres apresente características positivas para serem trabalhadas na sala de aula, esta, em sua grande maioria, mostra-se distante do que seria ideal para que se possa construir uma visão realmente crítica e bem esclarecida sobre a temática junto aos alunos.

É o animal selvagem, que vive na natureza sem contato com o homem (Professor 9). Animal silvestre é aquele que vive na selva (Professor 20).

Nas definições dos docentes é possível perceber um distanciamento entre o ambiente urbano (no qual os sujeitos sentem-se inseridos) e o ambiente considerado natural (onde a fauna vive). Barreto (1992 apud GRUN, 1996, p. 54), ao realizar uma pesquisa semelhante, percebeu nos argumentos utilizados pelos estudantes "a predominância de uma noção de meio ambiente exclusivamente naturalizada, que não comporta uma dimensão social, econômica e urbana". Nessa "naturalização" encontrada nesta pesquisa com os professores, o meio ambiente é a mata, o bosque, a selva, ou seja, não faz sentido a existência de um "meio ambiente urbano". Essa visão desconsidera a ação histórica dos seres humanos na natureza. Atualmente, grande parte das áreas naturais são afetadas pelas ações humanas, o que faz com que os animais silvestres precisem se adaptar a esses novos ambientes, muitas vezes sobrevivendo próximo a centros urbanos (ADAMS, 2005). Esta é uma problemática frequentemente enfrentada pelos educadores: os indivíduos não se sentem inseridos no meio ambiente, dificultando o processo educativo, por excluir a realidade do contexto, como se o problema não fosse de todos (CRESPO, 1998).

Ainda sob essa perspectiva, os sujeitos citaram apenas matas, florestas, campos e selvas como ecossistemas nos quais os animais silvestres são encontrados, não mencionando praias, lagos, e banhados, ecossistemas mais característicos da região de estudo e do país. Também, os animais citados como exemplo de animais silvestres são, em sua maior parte, de outros países (e.g. leão, tigre), percepção que entra em desacordo com a definição de que os animais silvestres são animais que vivem dentro dos limites do país (IBAMA, 1998). Tal dificuldade em citar os ecossistemas locais e o pouco conhecimento sobre a fauna da região é também, em grande parte, fruto desse distanciamento cultural que as pessoas possuem dos ambientes naturais. Durante toda a 
formação do indivíduo, assim como na mídia em geral, raramente os animais regionais são utilizados como referência, sendo muito mais comum o uso de animais de outros países (e.g. leões, zebras, girafas), ou de outras regiões do Brasil (e.g. onça da floresta Amazônica) como ícones no ensino. Em geral, os livros didáticos utilizados nas escolas seguem este padrão, não respeitando a herança cultural e as individualidades de cada região (NETO; FRACALANZA 2003), inclusive com relação ao ensino sobre animais silvestres.

Nesse ínterim, Freire (1980) destaca a necessidade de unir teoria à prática no processo de ensino. Desse modo, estas percepções, que se distanciam da compreensão ideal sobre o conceito de fauna silvestre, geram dificuldades para o processo de aprendizagem, principalmente ao tentar construir com os alunos uma consciência crítica sobre os animais silvestres e os crimes ambientais realizados contra eles. Se o meio ambiente que o aluno vê na sala de aula é a savana Africana ou a Floresta Boreal Canadense, e não o banhado ou o campo, que são ecossistemas característicos da região de estudo, é provável que a sua capacidade de compreender o conteúdo e de sentir-se sensibilizado a conservar o meio ambiente seja diminuída, pois o conteúdo fica preso ao campo teórico. O aluno que comumente passeia pelos ecossistemas da região com os seus pais, não vê relação da sua vida com o que lhe é passado em aula e, muito menos o aluno que se quer sai de sua vizinhança urbana. Assim, ao ver um terreno baldio, ou um riacho próximo a sua casa, os alunos muitas vezes não são capazes de reconhecê-lo como parte do meio ambiente, o que pode gerar problemas com o lixo e com a preservação das espécies locais.

No mesmo sentido, quando um animal exótico é apresentado na sala de aula como sinônimo de animal que vive na natureza, o aluno acaba possuindo dificuldade em compreender a diferença entre um animal silvestre, que vive na natureza do país, e um animal exótico, que vive na natureza de outros países. Outrossim, começa a entender que o animal que deve ser conservado é aquele que vive longe, o qual ele provavelmente só verá em zoológicos, mamíferos de grande porte e de beleza única, enquanto o gambá que aparece na sua casa à noite, o passarinho que fez ninho na árvore em frente à sua casa ou o lagarto que toma sol próximo ao cano de esgoto acabam sendo mortos por medo, por diversão ou apenas porque é o que normalmente se faz. De acordo com Loureiro

A práxis educativa transformadora é, portanto, aquela que fornece ao processo educativo as condições para a ação modificadora e simultânea dos indivíduos e dos grupos sociais; que trabalha a partir da realidade cotidiana visando a superação das relações de dominação e de exclusão que caracterizam e definem a sociedade contemporânea (LOUREIRO, 2003, p. 42).

Se o conceito de animais silvestres possui tantas concepções intrínsecas a ele, com o conceito de animais exóticos não é diferente. Na fala dos docentes fica claro que é o grupo que gera maior confusão sobre a sua definição, surgindo afirmações como:

(...) exóticos são utilizados na culinária e característicos de cada país (Professor

15). (...) exótico é o animal raro (...) exemplo: Mico Leão Dourado (Professor 13).

Poucos foram os professores que se aproximaram da definição tomada como próxima do conceito utilizado pelo IBAMA (1998), a saber:

São animais que não pertencem ao nosso ambiente, ou seja, não pertence à fauna de uma região e é levado para este ambiente (Professor 21). 
As denominações errôneas geralmente são decorrentes da falta de informação dos sujeitos e devido a vinculações equivocadas com o significado da palavra "exótico" propriamente dita que, no seu sentido figurado, também significa esquisito, extravagante, diferente (MICHELIS, 2009). A ausência de conhecimento, detectada entre os sujeitos, sobre o conceito de animal exótico apresenta-se como obstáculo para o ensino do tema na sala de aula. Se o aluno não é capaz de compreender a diferença entre um animal silvestre e um exótico, provavelmente não será capaz de compreender questões legislativas (e.g. quais animais podem ser adquiridos como animais de estimação com ou sem licença do IBAMA) e ecológicas (e.g. como a presença de cada categoria animal afeta os ecossistemas regionais) sobre a temática. Assim, é fundamental que os professores compreendam corretamente os conceitos mais basais relacionados às diferentes categorias de animais.

Em suma, destaca-se a necessidade de realizar atividades de formação continuada com os docentes relacionadas ao assunto dos animais silvestres, pois existe a necessidade de fortalecer seu conhecimento prévio. Como intitulado nesta categoria, entende-se que compreender corretamente as definições e as concepções mais intrínsecas ao conceito trabalhado é o primeiro passo para alcançar outras etapas de questionamento e então, finalmente, uma verdadeira Educação Ambiental com relação à temática.

\subsection{O tráfico e a cultura do cativeiro de animais silvestres na perspectiva dos docentes}

Para que seja possível desenvolver e aprofundar uma visão crítica sobre os animais silvestres, seu tráfico e cativeiro ilegal, é preciso que os docentes possuam conhecimento sobre a temática e sua realidade no país e no mundo. Assim, nesta categoria procurou-se investigar o saber e problematizar as concepções dos sujeitos sobre o assunto. O tráfico de animais silvestres, seu cativeiro ilegal e suas consequências foram definidos pelos professores como:

\footnotetext{
Para mim é alguém capturar animais silvestres para criar em casa como animal de estimação ou para vender (para ter lucro). As consequências são maus tratos, morte dos animais e muitas vezes acaba acontecendo até mesmo a extinção deles (Professor 12). Tirar macacos, aves da mata e vender! A consequência é a morte do animalzinho. (...) condições subumanas (...) (Professor 1). Vi documentários sobre o tráfico, e as precárias condições do seu transporte, muitos acabam morrendo na viagem. É um crime absurdo (Professor 18).
}

Como é possível perceber na fala dos docentes, em sua maioria, estes sabem definir, ao menos em parte, o que é o tráfico e o cativeiro ilegal de animais silvestres. A saber, compreende-se o tráfico como uma atividade de comércio e o cativeiro como a negação da liberdade, que, junto ao adjetivo ilegal, são atividades proibidas pela legislação do país (MICHAELIS, 2009), passíveis de resultarem em multa, apreensão e prisão para o indivíduo que praticá-las. As implicações atribuídas pelos sujeitos a essas atividades ilegais são sempre negativas, sendo citadas a extinção de espécies, maus tratos, mutilações, doenças e até morte causada pelo transporte e cativeiro ilegal, como tem sido visto em documentos que tratam do assunto, como o Relatório Nacional sobre o Tráfico de Animais Silvestres (RENCTAS, 2001). Os sujeitos deste estudo mostraram-se cientes sobre a importância de não capturar animais silvestres da natureza, devido a dois motivos principais citados por eles: para conservar a fauna e o equilíbrio do meio ambiente, demonstrando uma preocupação mais voltada à integridade da natureza e dos ecossistemas, e a para garantir o direito à liberdade dos animais que ao serem capturados 
são aprisionados, demonstrando uma preocupação com os próprios indivíduos, conforme evidencia-se nas suas falas:

(...) porque tirar os animais do seu ambiente, do seu viver natural, onde ele sabe como se alimentar, construir seus ninhos ou abrigos, se defender, para deixá-los presos apenas para serem vistos, expostos. (Professor 9). (...) prejudica os hábitos do animal, a cadeia alimentar e o equilíbrio ecológico como um todo (Professor 20). (...) pelo trabalho da conscientização já podemos ver espécies que não víamos há alguns anos. Exemplo: tucanos, veados, etc. (Professor 11).

Outras consequências apontadas foram multas e a prisão para quem pratica a atividade ilegal, demonstrando que os docentes conhecem, ao menos superficialmente, as consequências legais para quem trafica animais silvestres ou os mantém em cativeiro, que podem ser encontradas, em sua maioria, na Lei Federal de Proteção à Fauna no 5.197 de 1967 e na Lei de Crimes Ambientais no 9.605 de 1998. Atualmente observa-se na sociedade que, apesar da existência de leis e do conhecimento dos problemas gerados, o comércio ilegal de fauna só aumenta, já que o lucro obtido é considerável e o desejo de possuir um animal silvestre como animal de estimação é bastante difundido na região de estudo e no país como um todo (RENCTAS, 2001). Assim, mostra-se necessária a inserção da EA para que se possa ultrapassar as barreiras entre o que se sabe e como se atua na sociedade.

As consequências são muitas: destruição da fauna, mutilação dos animais e até a morte deles, e também prisão e multa (Professor 20).

É importante ressaltar que, apesar de todo o conhecimento demonstrado pelos professores sobre a temática, relações ou relatos sobre o tráfico, o cativeiro ilegal na região de estudo e nas escolas não foram mencionados, o que aponta para um saber que é baseado naquilo que se lê ou se assiste na mídia, e não naquilo que se presencia e se vive. Cabe aqui problematizar esse distanciamento percebido entre teoria e prática, pois essa visão provavelmente será, também, repassada para os alunos, que podem acabar com um discurso conservacionista que, de fato, não o compreendem. Atividades que busquem atuar como formação continuada de professores, devem atentar para essa situação, buscando, sempre, questionar o discurso estabelecido como ecologicamente correto por meio do que os sujeitos vivenciam.

A respeito da necessidade de autorização para possuir animais diferentes do comum (silvestres e exóticos), os sujeitos evidenciaram conhecer a imprescindibilidade da licença do IBAMA para tal fato. Quem não possui este conhecimento, compreende que existe uma legislação ou um órgão responsável. Uma prática comum na região das escolas estudadas é a captura dos animais direto na natureza, pelas próprias crianças e suas famílias, não só para realizar a venda, mas também para tê-los como animais de estimação. Esta situação demonstra a falta de informação das famílias locais que, muitas vezes, criam os animais silvestres em casa porque acreditam que estes serão melhores cuidados ou porque não conseguem refletir sobre o que significa a privação da liberdade para o animal. Em contraponto ao que se percebe na região, grande parte dos docentes demonstrou possuir consciência crítica sobre a posse de animais silvestre e exóticos:

Não gostaria de possuir para não acabar com a fauna (Professor 10). (...) porque eles são mais bonitos voando do que presos em um lugar restrito (Professor 19). Acho que prejudica, pelo trabalho da conscientização já podemos ver espécies que não víamos a alguns anos. Exemplo: tucanos, veados, etc. (Professor 13). Não gostaria, pois prejudica os hábitos do animal, a cadeia alimentar e o equilíbrio ecológico como um todo (Professor 21). 
Apenas um dos sujeitos demonstrou a ambição de possuir um animal diferente do comum, um lagarto, não especificando se um animal nativo ou exótico. No entanto, quase todos os sujeitos possuem ou conhecem pessoas que possuem pássaros em gaiolas. Alguns sabem informar se são legalizados, outros não, porém é comum conhecer alguém que possua um pássaro em cativeiro ilegal. Esta informação reafirma o que se sabe sobre o grande quantitativo de indivíduos que praticam essa atividade na região. No Brasil a intensa captura de passeriformes na natureza é direcionada ao mercado interno, pois a população mantém uma predileção especial por aves de gaiola, principalmente por pássaros canoros (RENCTAS, 2001). O olhar crítico dos docentes sob o cenário apresentado mostra-se bastante positivo sob a perspectiva da EA, pois estes concebem que, apesar dos benefícios que poderiam vivenciar possuindo um animal silvestre, os prejuízos causados ao animal e à natureza prevalecem. Assim, constata-se um discurso coerente com o que se procura alcançar com a EA crítica (GUIMARÃES, 2004).

Percebeu-se, nas respostas dos sujeitos, que existe na região e na sociedade em geral uma cultura de fascínio pelo desconhecido, pois possuir um animal exótico é considerado, por muitos, um sinal de diferenciação ou de status elevado. Essa percepção é, em grande parte, estendida também para quem possui animais silvestres em casa, principalmente pela população em geral. É preciso destacar que este entendimento é o que mais fomenta o tráfico de animais silvestres e exóticos pelo mundo, principalmente de animais raros, em risco de extinção, que possuem maior valor no mercado (RENCTAS, 2001). Em geral os indivíduos, mesmo sem vontade de possuir um animal silvestre, ao vê-lo nas mãos do traficante, em péssimas condições, acaba comprando-o, na tentativa de salvá-lo, sem perceber que esta atitude incentiva ainda mais o tráfico de animais (RENCTAS, 2001). Para a temática, a desmistificação destas ações, como atitudes que vem a beneficiar os animais e são pouco prejudiciais para o ambiente, é de suma relevância para que se possa ultrapassar o sabido superficial e alcançar uma compreensão crítica que resulte em uma real diminuição das atividades ilegais.

Compreende-se, por fim, que não lhes falta aos sujeitos conhecimento ou consciência crítica sobre a temática do tráfico e do cativeiro ilegal. No entanto, para que seja possível alcançar uma EA crítica com relação ao assunto, entende-se que é preciso adequar esses conhecimentos e o discurso para a realidade dos alunos e da escola. De acordo com Freire (1980) torna-se possível a mudança de valores e a superação dos paradigmas sociais, na perspectiva dos alunos, apenas quando estes percebem a conexão entre o que lhes é ensinado e o que vivenciam. Portanto, mostra-se relevante que atividades de EA e de formação continuada procurem desenvolver a capacidade dos sujeitos de tramarem o conhecimento que possuem no campo teórico ao que possuem no campo prático.

\subsection{A importância da EA em sala de aula e o papel do professor na construção de um entendimento crítico da temática dos animais silvestres}

Após compreender as concepções e compreensões dos professores sobre o assunto dos animais silvestres, as ameaças que sofrem e sua conservação, busca-se, nesta última categoria, questionar a importância da EA e do professor na sala de aula, quando tratando sobre a temática debatida. Assim, discute-se aqui, qual o contato e envolvimento que os professores possuem com o tema; se, e como tem tratado o conteúdo na sala de aula; ainda, se abordagens e teorias da EA tem permeado esse contexto, independente da área de estudo do professor. 
O tráfico e o cativeiro ilegal de animais silvestres são uma realidade em todas as escolas pesquisadas, alcançando especialmente seus alunos, que possuem informações bastante difundidas sobre pontos de venda ilegal de fauna e pessoas que possuem animais silvestres em cativeiro. O contexto acaba gerando grande número de animais apreendidos que são destinados ao NURFS/CETAS/UFPEL, órgão com o qual a população da região possui familiaridade (BEHLINIG; ISLAS, 2014). Assim, a problemática dos animais silvestres na região demonstra ser uma demanda presente na comunidade e destaca-se como importante "tema gerador" na sala de aula (FREIRE, 1985). Todas as informações as quais os sujeitos relataram ter tido acesso, sobre o tráfico e o cativeiro ilegal de animais silvestres, foram provenientes de palestras de órgãos governamentais e empresas, ou da mídia, que é um importante meio de difusão da informação e da "EA" não formal sobre temas de importância social e ambiental, pois é veículo de informação em massa, atingindo o grande público. Outros diversos meios de formação que poderiam tratar do tema não foram citados como fontes de informação pelos professores, como atividades extensionistas provenientes da Universidade (que fica próxima das escolas investigadas), a formação dos professores durante seu curso de magistério ou graduação ou outros cursos e processos de formação continuada. Nesse contexto, é preocupante que este assunto acabe passando tão despercebido pelos espaços de ensino formal investigados, pois é um tema que pode ser incentivador para abordagens transversais da EA.

Já participei de palestras da patrulha ambiental no curso Fonte de água viva (Professor 10). Já vi campanhas na TV e acho importante a realização de atividades desse tipo (Professor 18). Não participei (Professor 2).

A maior parte dos professores embora considerem o tráfico e o cativeiro ilegal de animais silvestres como negativos, digam ser favoráveis à conscientização da população sobre a temática e admitam a necessidade de utilizar a EA como arcabouço teóricometodológico de desenvolvimento do pensamento crítico junto aos alunos e, ainda, considerem o seu trabalho como veículo para que isto ocorra, afirmam não trabalhar o assunto em sala de aula. Poucos professores de Ciências afirmam que desenvolvem a temática durante o conteúdo programático que trata dos animais ou quando são designados para realizar projetos de EA na escola. Alguns sujeitos afirmam que nunca surgiu a oportunidade de trabalhar o tema em suas aulas, declaram que conversam com os alunos informalmente ou que não há material suficiente para trabalhar a temática de forma apropriada.

Sim, acho fundamental participar de atividades deste tipo (EA), mas não trabalhei em aula com meus alunos (Professor 11). Já trabalhei informalmente em sala de aula, para conscientização dos alunos das importâncias dos animais no ambiente em que vivemos (Professor 5). Já fiz alguns trabalhos bem interessantes, mas os materiais para obter mais informações são precários na internet e poucos documentários na tv (Professor 16).

A partir das falas acima questiona-se qual seria tal oportunidade esperada por alguns docentes para realizar atividades sobre a temática ou qual seria o real alcance de conversas informais sobre o assunto. Quando o professor se convence de que determinado assunto não possui relevância suficiente para ser trabalhado em sala de aula, indivíduos que tem menos acesso à informação acabam não entrando em contato com determinada temática, mantendo, por exemplo, o cativeiro ilegal e o tráfico ainda como uma atividade tão difundida (RENCTAS, 2001) entre a população que, sem conhecimento, é menos capaz de refletir a respeito dos malefícios da atividade. Como discutido anteriormente, a problemática dos animais silvestres e dos crimes cometidos contra eles possui raízes 
bastante profundas em visões legitimadas pela sociedade, necessitando que exista um esforço grande dos educadores para que se possa superar o senso comum. Para Loureiro (2005), existe um desafio na superação da perspectiva reducionista da crise ambiental, para a qual existe um grupo da sociedade caracterizado por essas visões:

Compreensão naturalista e conservacionista da crise ambiental; Educação entendida em sua dimensão individual, baseada em vivências práticas; despolitização do fazer educativo ambiental, apoiando-se em pedagogias comportamentalistas ou alternativas de cunho místico; baixa problematização da realidade e pouca ênfase em processos históricos; diluição da dimensão social na natural, faltando entendimento dialético da relação sociedadenatureza; responsabilização pela degradação posta em um homem genérico, fora da história, descontextualizado social e politicamente (LOUREIRO, 2005, p. 1475).

No mesmo sentido, outra colocação que deve ser destacada é que os docentes, apesar de exporem em seus questionários que compreendem a importância da realização de atividades de EA como as desenvolvidas nas escolas pelo projeto de extensão do NURFS/CETAS/UFPel, muitos evitaram permanecer na sala durante as palestras oferecidas. Esse fato questiona o envolvimento do professor em atividades complementares ao currículo escolar, principalmente de temas importantes como os referentes à EA. Propostas como a do projeto de EA aqui discutido possuem potencial para atuarem como atividades de formação continuada para os professores da rede pública. Esse potencial acaba desperdiçado quando o docente não valoriza a oportunidade e utiliza o tempo da atividade para realizar outras tarefas. Em sentido semelhante, quando projetos que tratam de temas referentes a EA são deixados para o professor de Ciências, como ocorrido em todas as escolas contatadas, poda-se o alcance que as atividades poderiam possuir para a formação continuada de docentes de todas as áreas de ensino, o que demonstra a dificuldade existente para implementar o caráter transdisciplinar da EA na educação (PRONEA, 2005).

$\mathrm{O}$ desinteresse percebido dos docentes pelas atividades oferecidas e a pouca permeabilidade da temática dos animais silvestres em seus planos de aula ocorrem, muitas vezes, porque o professor possui uma preocupação em vencer todo o conteúdo programado para o ano e acaba relegando a principal função social da escola que é formar alunos conscientes e cidadãos críticos (LOUREIRO, 2006). Alguns outros motivos são a falta de tempo, pois os professores possuem cargas horárias elevadas de trabalho, que demandam grande dedicação diária; e, por vezes, a própria indisposição do profissional, que muitas vezes é desiludido pela desvalorização salarial da classe, falta de oportunidades de formação continuada, ou por não encontrar apoio nas suas ideias para concretizar este tipo de iniciativa. Teixeira e Vale (2003) associam essas questões a problemas nas políticas públicas em relação ao ensino e também a aspectos falhos na formação do docente.

Sabe-se que campanhas, palestras e demais atividades complementares são importantes, mas há necessidade de um trabalho continuado neste caso. Reconhece-se a EA como elemento essencial ao combate dos problemas ambientais, entre eles o tráfico de animais silvestres, mesmo que exista dificuldade em realizar-se o processo educativo e a mudança de conduta na sociedade, frente a um resultado em longo prazo (GUIMARÃES, 2004). Ainda assim, o professor e a escola são peças fundamentais na sensibilização dos alunos para as temáticas da EA, destacando-se a necessidade de que se realizem atividades de formação continuada que tratem desses assuntos com os docentes da rede municipal. 


\section{Conclusões}

A partir do objetivo principal deste estudo - problematizar a temática do tráfico de animais silvestres e do cativeiro ilegal na sala de aula, a partir da compreensão da percepção de professores da educação básica - foi possível identificar o conhecimento e o interesse dos professores sobre o tema, bem como, a utilização da temática na escola. Ainda, por meio das respostas obtidas através dos questionários entregues aos professores, foi possível problematizar o papel da Educação Ambiental no ensino e na formação crítica do aluno que se depara com o tráfico e cativeiro ilegal dos animais silvestres no seu cotidiano.

Constatou-se que a temática do tráfico e do cativeiro ilegal de fauna tem sido preocupantemente negligenciada nos diversos espaços de ensino formal, o que tem promovido uma geração de professores não familiarizados com o tema $\mathrm{e}$, consequentemente, incapazes de trabalha-lo de forma crítica em sala de aula. A confusão entre as definições de animais silvestres e exóticos, bem como, o desconhecimento e desconexão com os ecossistemas e animais regionais demonstram a insuficiência de subsídios teóricos suficientes para trabalhar a temática na sala de aula.

Outrossim, a ideia do ambiente naturalizado, como um lugar afastado do cotidiano das pessoas; uma natureza na qual vivem os animais silvestres, mas os seres humanos só têm contato quando se propõe a viajar e interagir com o "meio ambiente"; são também concepções presentes na escrita dos sujeitos, reconhecidas como danosas para quem deseja ensinar sobre o tráfico e cativeiro ilegal de animais silvestres sob uma perspectiva crítica. Esses elementos, em conjunto, dificultam ainda mais a estimulação do sentimento de pertencimento nos alunos, ferramenta fundamental para a mudança de pensamento e para a reflexão.

Evidenciou-se, ainda, que, apesar de os docentes possuírem conhecimento sobre a existência e as consequências do tráfico e do cativeiro ilegal de animais silvestres em nível nacional, a maioria não trabalha o assunto em sala de aula, nem em projetos de ensino de Educação Ambiental. Estes, quando existentes, na maioria das vezes, são oriundos de ações que não partem da escola. As questões relacionadas aos animais silvestres e sua conservação não possuem grande abrangência no currículo, nos projetos extracurriculares ou na formação continuada dos professores das escolas investigadas, pois a temática não tem sido reconhecida nas escolas como de fundamental relevância, o que pode gerar graves prejuízos para a conservação dos animais silvestres no futuro. Destaca-se, assim, a importância da temática para o ambiente escolar e a necessidade de que exista uma construção coletiva das ações de EA, a fim de conhecer as demandas dos alunos, da comunidade e da escola, para que se possa preparar os sujeitos para lidarem com as problemáticas ambientais as quais se depararão ao longo de suas vidas.

Por fim, o combate ao tráfico de animais silvestres, assunto relevante de abrangência nacional, passa, necessariamente, pela conscientização da nossa sociedade, pela disponibilidade de informações e pela organização dos órgãos de controle ambiental, sendo a escola e os professores elementos fundamentais contra essas ações criminosas. Portanto, se faz necessário o investimento na formação de professores com ênfase na Educação Ambiental, incentivando o desenvolvimento do olhar crítico nas situações cotidianas, para que problemáticas como o tráfico e o cativeiro ilegal possam ser contempladas com ações educacionais significativas em sala de aula.

\section{Referências}


ADAMS, L. W. Urban wildlife ecology and conservation: a brief history of the discipline. Urban ecosystems, v. 8, n. 2, p. 139-156, 2005.

BEHLING, G. M.; ISLAS, C. A. Extensão universitária, educação ambiental e ludicidade na preservação de animais silvestres. Revista Conexão UEPG, v. 10, n. 1, p. 128-139, 2014.

BRASIL. Lei Federal ${ }^{\circ}$ 5.197, de 3 de janeiro de 1967. Lei de proteção à fauna. Dispõe sobre a proteção à fauna e dá outras providências. Brasília, DF, 1967.

. Lei Federal no 9.605, de 1998. Lei de Crimes Ambientais. Dispõe sobre as sanções penais e administrativas derivadas de condutas e atividades lesivas ao meio ambiente, e dá outras providências. Brasília, DF, 1998.

. Ministério da Educação. Secretaria de Educação Média e Tecnológica Fundamental. Parâmetros Curriculares Nacionais. Brasília, DF, 1998.

Lei $\mathrm{n}^{\circ} 9.795$ de 1999. Política Nacional de Educação Ambiental. Dispõe sobre a educação ambiental, institui a Política Nacional de Educação Ambiental e dá outras providências. Brasília, DF, 1999.

CRESPO, S. Educar para a sustentabilidade: a educação ambiental no programa da agenda 21. NOAL, F. O; REIGOTA, M.; BARCELOS, V.H.L. (Orgs.). Tendências da educação ambiental brasileira. Santa Cruz do Sul, RS: EDUNISC, p. 211-225, 1998.

DESTRO, G. F. G.; BARRETO, R.; SABAINI, R. M.; BORGES, R. C.; PIMENTEL, T. L. Efforts to combat wild animals trafficking in Brazil. INTECH Open Access Publisher, 2012.

FREIRE, P. Conscientização: teoria e prática da libertação - uma introdução ao trabalho de Paulo Freire. 3. ed. São Paulo: Moraes, 1980.

. A importância do ato de ler. 10. ed. São Paulo: Cortez/Autores Associados, 1985.

Medo e ousadia: o cotidiano do professor. Editora Paz e Terra, 2014.

GRÜN, M. Ética e Educação Ambiental: a conexão necessária. 11. ed. Campinas: Papirus, 1996.

GUIMARÃES, M. A formação de Educadores Ambientais. 3. ed. Capinas: Papirus, 2004.

IBAMA. Portaria no 93/1998, de 07 de julho 1998, Importação e Exportação Fauna Silvestre, Brasília, DF, 1998.

JACOBI, P. Educação e meio ambiente: transformando as práticas. Revista Brasileira de Educação Ambiental, Brasília, n. 0, p. 28-35, 2004.

LACAVA, U.; ROCHA, F. M.; SARACURA, V. Tráfico de animais silvestres no Brasil: um diagnóstico preliminar. WWF-Brasil, Brasília, 2000.

LEVINSHON, T; PRADO, P. Quantas espécies há no Brasil? Megadiversidade, v. 1, n. 1, p. 3642, jul. 2005.

LOUREIRO, C. F. Premissas teóricas para uma educação ambiental transformadora. Ambiente e Educação, Rio Grande, v. 8, p. 37-54, 2003. 
Complexidade e dialética: contribuições à práxis política e emancipatória em Educação Ambiental. Educação \& Sociedade, v. 26, n. 93, p. 1473-1494, 2005.

Trajetórias e Fundamentos da Educação Ambiental. 2. ed. São Paulo: Cortez, 2006.

MICHELIS. Dicionário Online Michelis. São Paulo: Editora Melhoramentos Ltda, 2009.

MORAES, R. Análise de conteúdo. Revista Educação, v. 22, n. 37, p. 7-32, 1999.

MORAES, R.; GALIAZZI, M. C. Análise textual discursiva: processo reconstrutivo de múltiplas faces. Ciência \& Educação, v. 12, n. 1, p. 117-128, 2006.

NETO, J. M.; FRACALANZA, H. O livro didático de ciências: problemas e soluções Ciência \& Educação, v. 9, n. 2, p. 147-157, 2003.

PRONEA. Programa Nacional De Educação Ambiental do Ministério do Meio Ambiente, Diretoria de Educação Ambiental; Ministério da Educação. Coordenação Geral de Educação Ambiental. 3. Ed. Brasília, DF: Ministério do Meio Ambiente, 2005.

REDFORD, K. H. The empty forest. BioScience, California, v. 42, n. 6, p. 412- 422, 1992.

RENCTAS. $1^{o}$ Relatório Nacional sobre o Tráfico da Fauna Silvestre. Brasília, 2001.

TAMAIO, I. O professor na construção do conceito natureza: uma experiência de educação ambiental. São Paulo: Annablumme/WWF, 2002.

TARDIF, M. Saberes docentes e formação profissional. 3. ed. Petrópolis, RJ: Vozes, 2002

TEIXEIRA, P. M. M.; VALE, J. M. F. Ensino de Biologia e cidadania: problemas que envolvem a prática pedagógica de educadores. In: NARDI, R. (Org.). Educação em Ciência: da pesquisa à prática docente. 3. ed. São Paulo: Escrituras, p. 23-40, 2003.

WEBSTER, D. The Looting and Smuggling and Fencing and Hoarding of Impossibly Precious, Feathered and Scaly Wild Things, N.Y. Times Mag, New York, n. 28, 1997.

Versão recebida em: 28/07/2015

Aceite em: 11/11/2015 